\title{
Minocycline-induced Cartilage Hyperpigmentation Mimicking Alkaptonuria in a Patient with Knee Pain
}

JENNIFER R. STICHMAN, MD, FACR, Divisions of Rheumatology and General Internal Medicine, Department of Medicine, Denver Health Medical Center, and Assistant Professor of Medicine, University of Colorado School of Medicine, Denver, Colorado, USA; STERLING G. WEST, MD, MACP, MACR, Professor of Medicine, Division of Rheumatology, Department of Medicine, University of Colorado School of Medicine, Denver, Colorado, USA. Address correspondence to Dr. J.R. Stichman, 301 West 6th Ave., Mail Code 3251, Denver, Colorado 80204, USA. E-mail: jennifer.stichman@dhha.org.

J Rheumatol 2016;43:825; doi:10.3899/jrheum.151298

Ochronosis is the bluish-black discoloration of tissues typically due to the rare autosomal-recessive metabolic disorder alkaptonuria, caused by a mutation of the $H G D$ gene on chromosome 3 . This gene mutation results in a deficiency of homogentisate 1,2-dioxygenase, leading to the accumulation and deposition of homogentisic acid in cartilage and other connective tissues. This in turn causes pigmentation, tissue degeneration, and premature osteoarthritis. Ochronosis is rarely reported following exposure to exogenous substances.

A 55-year-old man was referred to our rheumatology clinic by his orthopedist for evaluation of ochronosis. He was originally seen for knee pain and underwent arthroscopy for possible meniscal tear. Arthroscopy revealed darkened, otherwise normal cartilage (Figure 1A) and biopsy revealed pigmented deposits (Figure 1B), prompting his referral. On our evaluation, he was found to have areas of nail and skin hyperpigmentation (Figure 1C). Ear cartilage and sclera were normal. A urine sample failed to darken on exposure to sunlight or with the addition of $10 \%$ sodium hydroxide (alkaline agent). Two separate 24-h urine collections for organic acids were negative for an elevated homogentisic acid level, ruling out alkaptonuria. On subsequent questioning, he reported that he had taken minocycline (100 mg daily) for over 5 years for treatment of adult-onset acne. Minocycline has been reported to cause hyperpigmentation resembling ochronosis with longterm use, typically with total exposure $>100 \mathrm{~g}^{1}$. The longterm effects of pigment accumulation from minocycline are unknown, but were not associated with cartilage destruction in our patient.

\section{REFERENCE}

1. Suwannarat P, Phornphutkul C, Bernardini I, Turner M, Gahl WA. Minocycline-induced hyperpigmentation masquerading as alkaptonuria in individuals with joint pain. Arthritis Rheum 2004;50:3698-701.

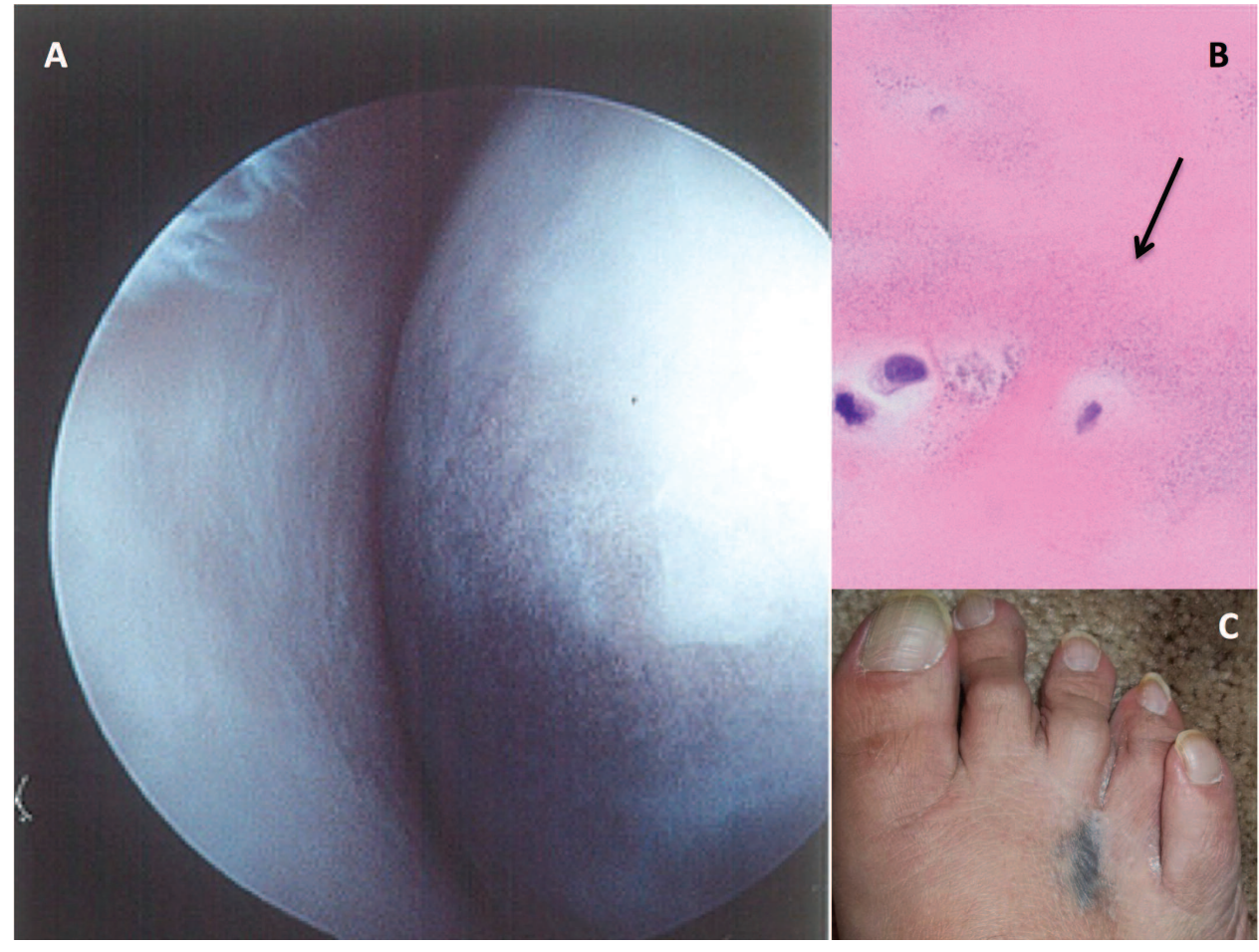

Figure 1. (A) Arthroscopy with darkened, otherwise normal cartilage. (B) Biopsy revealed pigmented deposits. (C) Areas of nail and skin hyperpigmentation.

$$
\text { Personal non-commercial use only. The Journal of Rheumatology Copyright @ } 2016 \text {. All rights reserved. }
$$

